\title{
Mycobacterial glycolipids di-O-acylated trehalose and tri-O-acylated trehalose downregulate inducible nitric oxide synthase and nitric oxide production in macrophages
}

\author{
Patricia Espinosa-Cueto', Marina Escalera-Zamudio², Alejandro Magallanes-Puebla', Luz María López-Marín³, \\ Erika Segura-Salinas ${ }^{1}$ and Raúl Mancilla ${ }^{1 *}$
}

\begin{abstract}
Background: Tuberculosis (TB) remains a serious human health problem that affects millions of people in the world. Understanding the biology of Mycobacterium tuberculosis (Mtb) is essential for tackling this devastating disease. Mtb possesses a very complex cell envelope containing a variety of lipid components that participate in the establishment of the infection. We have previously demonstrated that di-O-acylated trehalose (DAT), a noncovalently linked cell wall glycolipid, inhibits the proliferation of T lymphocytes and the production of cytokines.

Results: In this work we show that DAT and the closely related tri-O-acylated trehalose (TAT) inhibits nitric oxide (NO) production and the inducible nitric oxide synthase (iNOS) expression in macrophages (MØ).

Conclusions: These findings show that DAT and TAT are cell-wall located virulence factors that downregulate an important effector of the immune response against mycobacteria.
\end{abstract}

Keywords: Tuberculosis, Glycolipids, Nitric oxide, iNOS

\section{Background}

Tuberculosis (TB) remains a serious health problem, with 8.8 million new cases and 1.4 million deaths reported in 2013 [1]. An understanding of disease pathogenesis could lead to a rational strategy to fight TB. Along with the prolonged coevolution with man, the bacillus has developed the ability to neutralize the macrophages (MØ), which are usually very efficient to kill intracellular microbes. The adaptive capacity of mycobacteria resides mainly in the cell wall, a structure of high complexity composed of a covalently linked arabinogalactan-peptidoglycan backbone with covalently attached mycolic acids, as well as abundant noncovalently linked lipid components [2]. It is known that several of these lipids are capable of blocking the antimycobacterial host responses. Indeed, virulence of Mtb isolates has been associated with the cell wall lipid

\footnotetext{
* Correspondence: mancilla@biomedicas.unam.mx

${ }^{1}$ Departamento de Inmunología, Instituto de Investigaciones Biomédicas,

Universidad Nacional Autónoma de México, Mexico City, Mexico

Full list of author information is available at the end of the article
}

components. For instance, the high pathogenicity of $\mathrm{W} /$ Beijing isolates seems to be related to cell wall lipids that upregulate a TH2 immune response that favors the infection [3]. Once delipidated, the mycobacteria lose the ability to block the fusion of the phagosome with the lysosome, and total extractable lipids inhibit T-cell and MØ functions [4]. Peptidoglycan inhibits the macrophage response to IFN- $\gamma$ at a transcriptional level [5]. Among the cell wall glycolipids, excels the effects on immune response caused by trehalose-6,6-dymicolate (cord factor), which promotes pro-inflammatory cytokine production, influences the persistence of mycobacteria within $M \varnothing$ and retards phagosome maturation [6]. Also important is the lipoarabinomannan, as it regulates phagosome maturation and inhibits acquired immunity [7]. We have shown previously that di-O-acylated trehalose (DAT), a non-covalently attached mycobacterial cell wall glycolipid, downregulates the proliferation of $\mathrm{T}$ cells and the production of cytokines, two essential features of adaptive immunity [8]. In this work, we show that DAT 
and its more heavily lipidated homologue, tri-O-acylated trehalose (TAT), downregulates the inducible nitric oxide synthase (iNOS) expression and nitric oxide (NO) production in MØs, which are effector components that are important in the immune response against mycobacteria.

\section{Results}

Isolation of DAT and TAT from mycobacterium fortuitum

$M$. fortuitum has been used as an alternative source of acyl trehaloses, which belong to a lipid family featuring virulent Mtb strains [9]. Non-mycoloyl fatty acylated trehaloses occur in virulent strains of the Mtb complex but are either absent or minimally represented in avirulent members of the complex, such as the H37Ra Mtb isolate or the vaccine strains $M$. bovis BCG and SO2 [9]. However, DAT and TAT have been described in M. fortuitum [10] and, taken from this source, they have been found to mimic both antigenicity and immunoregulation activities of the Mtb native compounds [8, 11]. Thin-layerchromatography analyzes of crude lipid extracts are shown in Fig. 1. Acid/anthrone reagent was used to display sugar-containing lipids, which developed as blue spots, allowing the identification of two medium-polarity glycosyl-containing lipids in $M$. fortuitum (Fig. 1a). According to their mobility in chloroform-methanol (80:20, $\mathrm{vol} / \mathrm{vol}$ ) onto the silica gel layer, glycolipids with $\mathrm{Rf}$ values of 0.37 and $0.64-0.68$ were tentatively identified as DAT and TAT, respectively (Fig. 1b). After their purification by column chromatography on Florisil and silica-gel solid-phase extraction, the isolated glycolipids were further characterized by Fourier Transform Infra-Red (FTIR) spectroscopy, (Fig. 1c). Both spectra share characteristic bands of glycosylated lipids, as expected. The characteristic band at 3320 and $3350 \mathrm{~cm}^{-1}$ indicates the presence of an oxygen-hydrogen bond in hydroxyl groups $(-\mathrm{OH})$ in the sugar moieties of DAT y TAT, respectively. Absorption bands at $2922 \mathrm{~cm}^{-1}$ and 2853 $\mathrm{cm}^{-1}$ were assigned to the symmetric stretch of methylene $\left(-\mathrm{CH}_{2}-\right)$ and methyl $\left(-\mathrm{CH}_{3}\right)$ groups of aliphatic chains, respectively. The peak located at $1647 \mathrm{~cm}^{-1}$ indicates the presence of carboxyl ester groups (-CO-O-). Finally, the characteristic FTIR fingerprint of mycobacterial acylated trehaloses is shown in the region from about 1500 to $500 \mathrm{~cm}^{-1}$, due to all manner of bending vibrations of these molecules, the so-called mycosides $\mathrm{F}$ [10]. The concentration of endotoxin was measured by the Lymulus assay test and was undetectable.

\section{DAT and TAT inhibit no production by Murine MØs}

To analyze the effects of DAT and TAT on NO production in bone marrow-derived MØs, we first established the optimal conditions to carry out the assay. The MØs activated with 500ng of LPS released $23.4 \mu \mathrm{M} / \mathrm{ml}$ of NO in $24 \mathrm{~h}$. When 20 ng of TAT were added to the cells, NO production was reduced by $59.52 \%$ (Fig. 2a, b). Interestingly, the inhibitory effects of TAT on NO production induced by IFN- $\gamma$ were higher (up to $90.9 \%$ ) (Fig. 2a, b). As for the effects of DAT, the inhibition of the production of NO induced by LPS was almost total and up to $78.2 \%$ in cells activated with IFN- $\gamma$ (Fig. 2c, d).

\section{DAT and TAT inhibit the inos expression in Murine MØ}

In view of the involvement of iNOS in the regulation of NO production, we studied the effects of DAT and TAT on iNOS expression induced either by LPS or IFN- $\gamma$ in bone marrow-derived MØs (Fig. 3). These assays showed

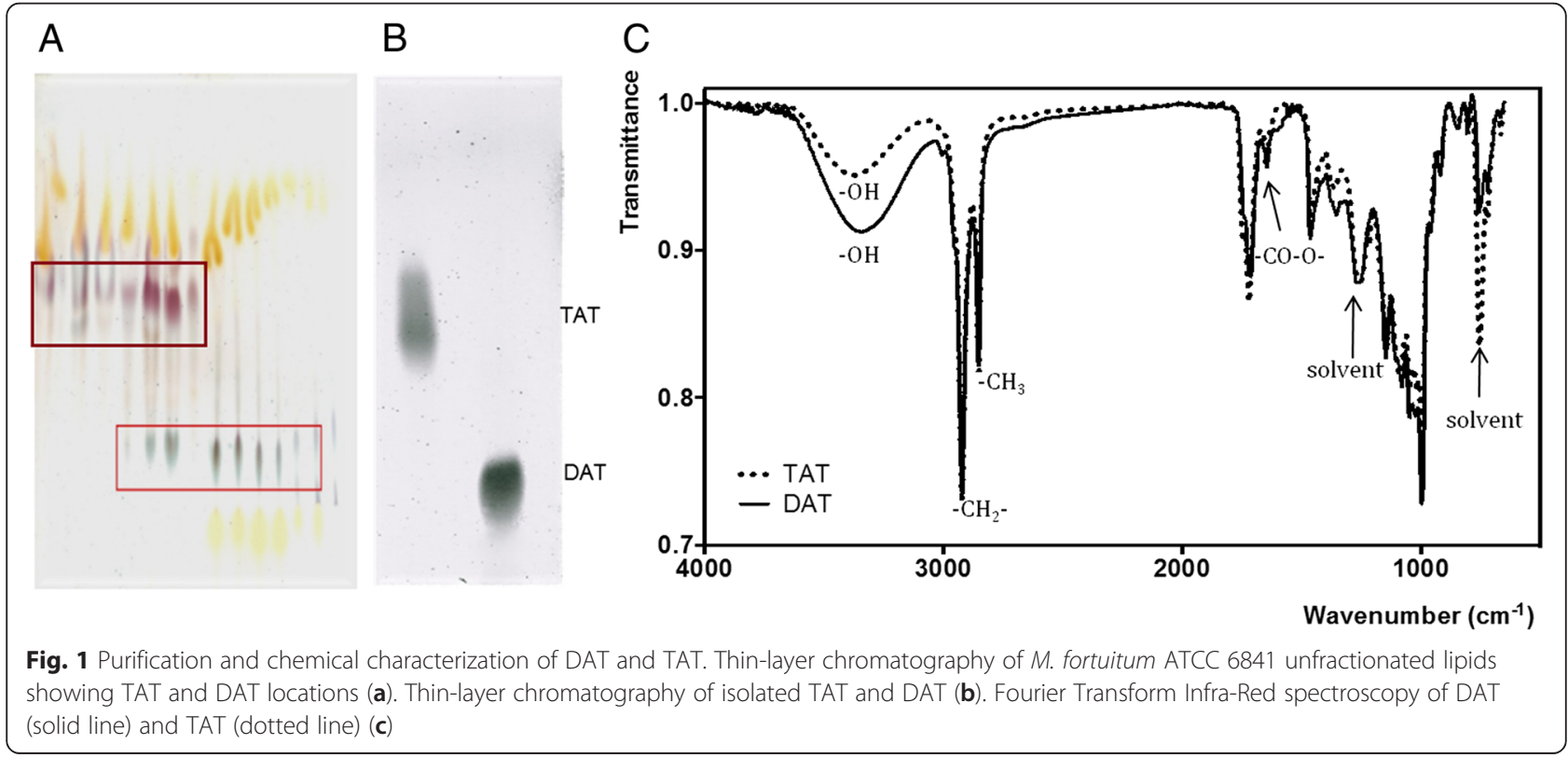




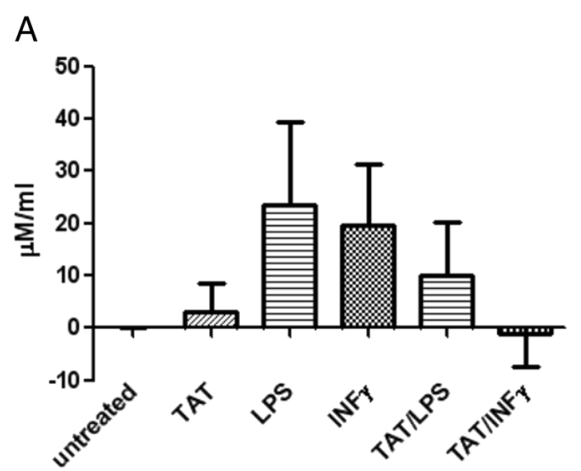

C

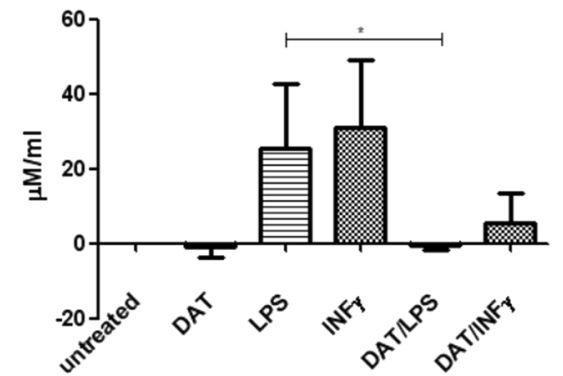

B

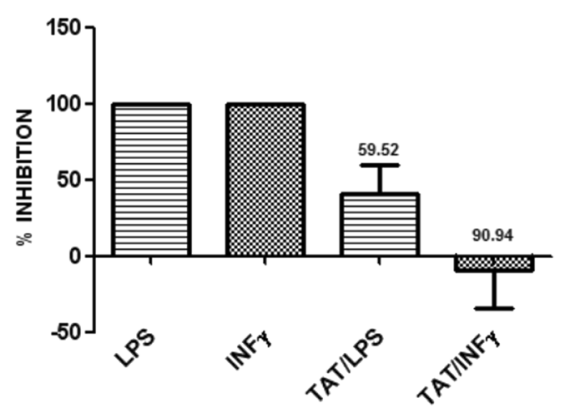

D

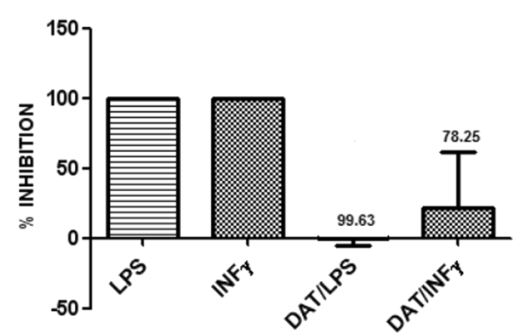

Fig. 2 DAT and TAT downregulate NO production induced by LPS and IFN- $\gamma$ in bone marrow-derived M $\varnothing$ s. The isolated TAT or DAT were dissolved in hexane/methanol and placed in the wells. After solvent evaporation $1 \times 10^{6}$, MØs were added to the wells. Afterward LPS (500ng) or IFN- $y$ (250ng) were added to the cells. After $24 \mathrm{~h}$, the culture medium was collected, and NO was measured by the Griess reaction (a, $\mathbf{c}$ ). The percent inhibition of NO production induced by TAT $(\mathbf{b})$ and DAT $(\mathbf{d})$ are shown. Results of four experiments are presented. Data regarding LPS against DAT/LPS was analyzed using an unpaired t-test with Welch's correction to assess the statistical significance * $\mathrm{p}<0.05$

that TAT reduced up to $39.18 \%$ the expression of iNOS in cells activated with LPS. Similarly, the expression of iNOS in cells activated with IFN- $\gamma$ was downregulated by TAT in $32.6 \%$ (Fig. 3a, b). DAT also inhibited the expression of iNOS in $31.2 \%$ after activation with LPS and $39.5 \%$ when the cells were stimulated with IFN- $\gamma$ (Fig. 3d, e). Western blot analyzes also showed a decreased expression of iNOS after exposure of MØs to acyl-trehaloses. However, this technique indicated a more pronounced effect on the di-O-acylated molecule (Fig. 3c, f).

\section{Discussion}

$\mathrm{NO}$ is a bioactive gas produced by MØs activated with INF- $\gamma$ through the catalytic action of iNOS [12]. The production of NO is an important host defense mechanism in Mtb infection. Mice with disrupted iNOS genes are highly susceptible to TB and develop progressive disease [12]. In murine models of tuberculosis, $\mathrm{NO}$ is known to enhance the phagosomal maturation, thus promoting macrophage killing of the bacilli $[12,13]$. The relevance of $\mathrm{NO}$ for controlling the bacilli in humans remains controversial. However, various data support that the NO/iNOS system plays a role in tuberculosis disease. For instance, Mtb triggers the production of $\mathrm{NO}$ and
iNOS in MØs from both healthy and tuberculous individuals $[14,15]$. Patients with active pulmonary tuberculosis exhale NO, which is associated with increased production of iNOS by alveolar macrophages [16]. Moreover, histopathologic studies have shown that iNOS is expressed in human tuberculous granulomas [17]. Recently, our group demonstrated the expression of iNOS in MØs and multinucleated Langhans-type giant cells, as well as extensive MØs nitrosylation within bovine tuberculosis granulomas [18]. Finally, some iNOS polymorphisms seem to be associated with an increased susceptibility to TB in humans [19].

At high concentration, NO kills Mtb very efficiently in vitro while, at lower doses, it exhibits a bacteriostatic and hormetic effects [20]. The cell damage induced by NO may result in DNA mutations and strand breaks or nitrosylation of key proteins, including enzymes that may lose activity [21]. The ability of Mtb to survive and replicate within the $M \emptyset \mathrm{s}$, even in the presence of adverse factors such as NO, seems essential for the development of the infection. The identification of mechanisms used by mycobacteria to evade nitrosative damage is an important goal since it could help to develop strategies for treating or preventing TB. For instance, there are Mtb genes known to be involved in resistance to the damage induced 


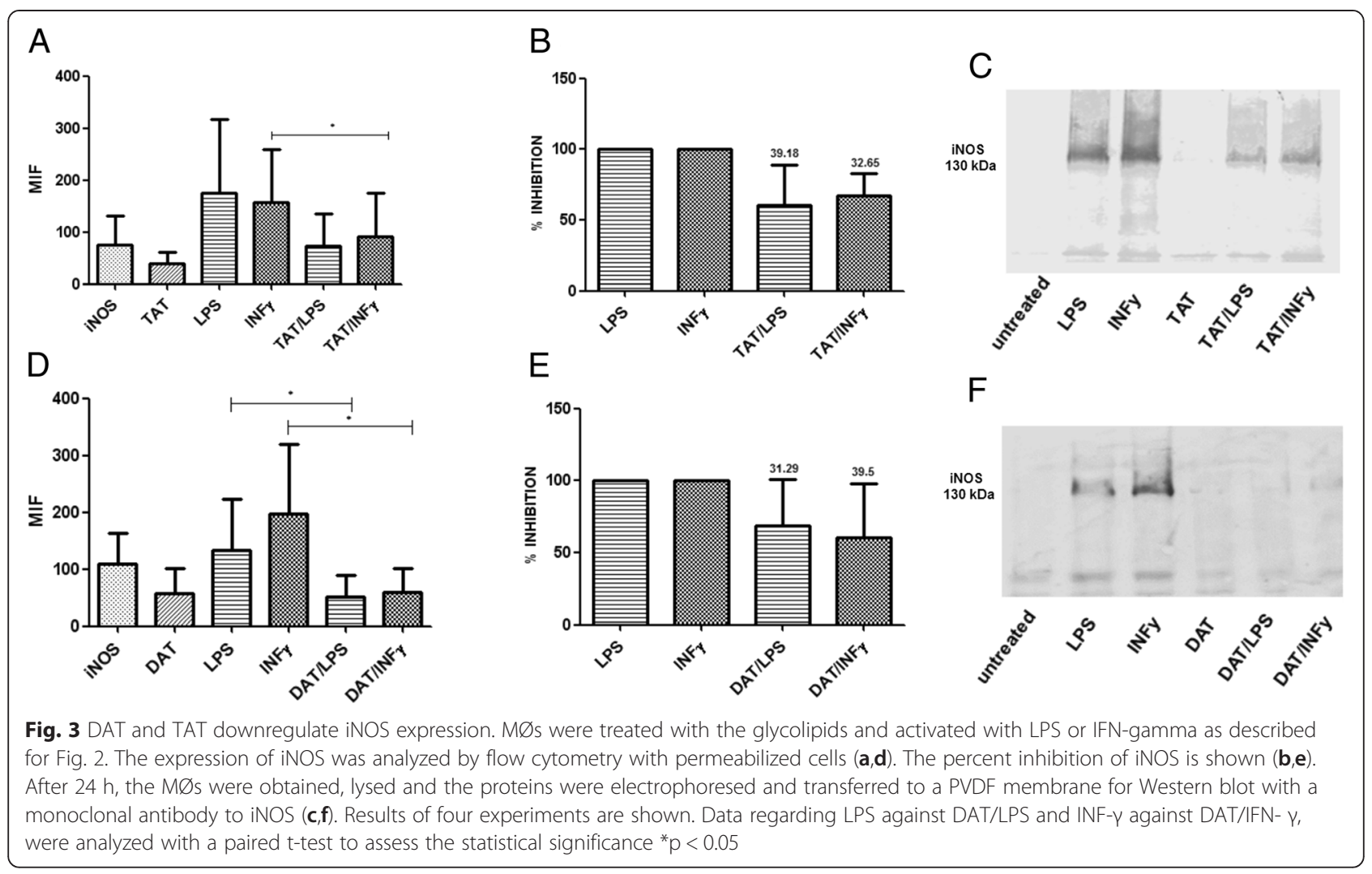

by nitric oxide [22]. The results reported in this study show that the structurally related TAT is to be considered a potential virulence factor of mycobacteria as well. TAT is highly recognized by serum antibodies in individuals with active tuberculosis [11], a fact that was once attributed to cross-reactivity of TAT to anti-DAT antibodies. More recently, structural studies of Mtb glycolipids have evidenced the presence of TAT in both clinical isolates and typical strains [23, 24]. To the best of our knowledge, this is the first report dealing with a biological activity of TAT on antimycobacterial immune response. Further studies will be needed to clarify whether the fatty acyl structural differences between species may account for the effects herein described.

\section{Conclusions}

We show that DAT and TAT, two glycolipids located on the cell wall behave as virulence factors engaged in the downregulation of NO and iNOS, therefore representing a potential weapon of the mycobacteria against the innate immune response.

\section{Methods}

\section{Ethics statement}

Use of animals and experimental procedures were reviewed and approved by the Bioethics Committee of our Institute following established protocols.

\section{Isolation of glycolipids}

M. fortuitum ATCC 6841 was used to isolate DAT and TAT, which are similar in M. fortuitum and Mtb. Noncovalently linked lipids were extracted from live bacilli using $\mathrm{CHCI}_{3} / \mathrm{CH}_{3} \mathrm{OH}(1: 2, \mathrm{vol} / \mathrm{vol})$ and $\mathrm{CHCI}_{3} / \mathrm{CH}_{3} \mathrm{OH}$ (2:1, vol/vol). Pooled extracts were dried and suspended in $\mathrm{CHCl}_{3} / \mathrm{CH}_{3} \mathrm{OH} / \mathrm{H}_{2} \mathrm{O}(4: 2: 1, \mathrm{vol} / \mathrm{vol} / \mathrm{vol})$. After that, crude lipid extracts were dissolved in chloroform and applied to a Florisil column (Biotecna Corp., Miami, FL, USA). The elutions were performed with chloroform and methanol and fractionation of lipids was monitored by thin-layer chromatography (TLC) on silica gel-60 $\mathrm{F}_{254}$ coated plates (E. Merck, Darmstadt, Germany) developed with: $\mathrm{CHCl}_{3} / \mathrm{CH}_{3} \mathrm{OH}(9: 1, \mathrm{vol} / \mathrm{vol})$ as solvent I; $\mathrm{CHCI}_{3} / \mathrm{CH}_{3} \mathrm{OH}(8: 2, \mathrm{vol} / \mathrm{vol})$, as solvent II; or $\mathrm{CHCI}_{3} /$ $\mathrm{CH}_{3} \mathrm{OH} / \mathrm{H}_{2} \mathrm{O}$ (60:12:1, vol vol/vol), as solvent III. The sugar-containing compounds were visualized by spraying plates with $2 \%$ anthrone in concentrated $\mathrm{H}_{2} \mathrm{SO}_{4}$ followed by heating at $110{ }^{\circ} \mathrm{C}$. Acylated trehaloses appeared as anthrone-positive lipids (blue spots) with a Rf value of 0.37 for DAT and a Rf value of $0.64-0.68$ for TAT. A final purification was carried in a TLC on silica gel-60 coated plates with a thickness of $0.5 \mathrm{~mm}$ (E. Merck, Darmstadt, Germany). The lipids were recovered from the plates and examined as mentioned before. The fractions with purified DAT were pooled, dried and subjected to the Lymulus test to verify 
endotoxin contamination. A similar procedure was followed to purify TAT.

\section{Characterization of dat and tat by fourier transform infrared spectroscopy}

Fourier transform infrared spectroscopy (FTIR) analyses of the lipids were recorded in a Vector 33 FTIR spectrometer (Bruker Corporation, Billerica, MA, USA), equipped with an attenuated total reflection (ATR) module. About $0.5 \mathrm{mg}$ of the product was dissolved in $200 \mu \mathrm{l}$ chloroform-methanol $(9: 1, \mathrm{vol} / \mathrm{vol})$ and placed into the ATR cell. FTIR spectrum measurement was performed in wave number range of $4000-450 \mathrm{~cm}^{-1}$.

\section{Assays to study the effects of dat and tat on nitric oxide production in macrophages}

Six to seven week old Balb/c-J mice were used. To obtain MØs, bone marrow cells were flushed from femurs and tibias and cultured in RPMI 1640 with $20 \%$ FBS, supplemented with $1 \%$ non-essential aminoacids, $1 \%$ of antibiotic-antimycotic and $1 \%$ sodium pyruvate (Invitrogen, Eugene, OR, USA). Cells were grown at $37{ }^{\circ} \mathrm{C}$ with $5 \% \mathrm{CO}_{2}$. At day $10, \mathrm{MØs}$ were obtained, and the cell viability was assessed with Trypan blue. In preliminary experiments to determine the capacity of bone marrowderived $\mathrm{MØs}$ from Balb/c-J mice to produce NO, the cells were treated with various amounts of LPS (E.coli B55:05; Sigma Chemical Co, St Louis, MO, USA) or recombinant IFN- $\gamma$ (BioLegend, San Diego, CA, USA). The glycolipids were dissolved in hexane:ethanol (1:1, v/ v). To each well, $20 \mu \mathrm{g}$ glycolipid in $100 \mu \mathrm{l}$ hexane:ethanol were added and allowed to evaporate to dryness; control wells received solvent alone. Then, $1 \times 10^{6} \mathrm{M} \varnothing \mathrm{s}$ were added to the wells and incubated for $24 \mathrm{~h}$ at $37{ }^{\circ} \mathrm{C}$ with $5 \% \mathrm{CO}_{2}$. Afterward, $500 \mu \mathrm{g}$ LPS or $250 \mathrm{ng}$ IFN- $\gamma$ were added to the wells. Control wells with only hexane:ethanol, DAT or TAT were included. After $24 \mathrm{~h}$ the isolated supernatants were mixed with an equal volume of Griess reagent ( $1 \%$ sulfanilamide, $0.1 \%$ N-1naphthylethylenediamine dihydrochloride, and $2 \%$ phosphoric acid) (Promega Co., Madison,WI, USA) and incubated at room temperature for $10 \mathrm{~min}$. Absorbance was measured at $550 \mathrm{~nm}$.

\section{Western blot and flow cytometry to determine the expression of iNOS in macrophages treated with DAT and TAT}

To investigate the expression of iNOS by MØs treated with the glycolipids, the cells were lysed with RIPA buffer and the proteins were separated in 7.5 \% PAGE-SDS gels, transferred to a PVDF membranes and incubated overnight with a monoclonal antibody diluted 1:100 to murine iNOS (BD Biosciences, San Diego, CA, USA). Membranes were extensively rinsed with PBS and incubated with a secondary antibody to mice IgG diluted 1:200, $2 \mathrm{~h}$ at room temperature. The reactive bands were visualized by chemiluminescence with SuperSignal West Dura kit (Pierce, Rockford, IL, USA) or with $\mathrm{DAB} / \mathrm{H}_{2} \mathrm{O}_{2}$. For flow cytometry, $5 \times 10^{5}$ cells were fixed with paraformaldehyde $1 \%$, permeabilized with saponin $0.05 \%$ and incubated $1 \mathrm{~h}$ with the monoclonal antibody diluted 1:200 to murine iNOS. The cells were rinsed and incubated for $1 \mathrm{~h}$ with a secondary antibody labeled with FITC. The cells were analyzed in a Beckton Dickinson cytofluorometer (San Diego, CA, USA). As a control, a monoclonal antibody of the same isotype was used.

\section{Statistical analysis}

Statistical analysis was performed using the standard statistical software Prism version 5.0, GraphPad Software, (San Diego, CA, USA). NO and iNOS production by cells was expressed as inhibition percentages, where LPS or IFN- $\gamma$ induced levels, in the absence of mycobacterial lipids, were taken as $100 \%$.

\section{Competing interests}

The authors declare that they have no competing interests.

\section{Authors' contributions}

PEC was in charge of culturing cells, cytofluorometry assays, and statistical analysis. MEZ participated in the project design, cell culture, and assays to test the effects of glycolipids on macrophages. AMP contributed to the analysis of results, writing and submission of the manuscript. LMLM isolated and characterized the lipids, analyzed results and reviewed the manuscript. ESS isolated glycolipids. RM designed experiments, analyzed results and wrote the manuscript. All authors read and approved the final manuscript.

\section{Acknowledgments}

This work was supported by grant IN-207211 from the Programa de Apoyo a Proyectos de Investigación e Innovación Tecnológica (PAPIIT), Universidad Nacional Autónoma de México. G. Hernández-Padrón performed FTIR analysis of lipids.

\section{Author details}

${ }^{1}$ Departamento de Inmunología, Instituto de Investigaciones Biomédicas, Universidad Nacional Autónoma de México, Mexico City, Mexico. ${ }^{2}$ Institute of Zoo and Wildlife Research, Leibniz, Germany. ${ }^{3}$ Centro de Física Aplicada y Tecnología Avanzada, Universidad Nacional Autónoma de México, S / N, Ciudad Universitaria, 04510 Mexico City, Mexico.

Received: 9 March 2015 Accepted: 8 June 2015

Published online: 23 June 2015

\section{References}

1. WHO. Global TB control report. 2014. http://www.who.int/tb/publications/ global_report/en/. Accessed 20 Feb 2015.

2. Daffé $M$, Draper $P$. The envelope layers of mycobacteria with reference to their pathogenicity. Adv Microb Physiol. 1998;39:131-203.

3. Manca C, Reed MB, Freeman S, Mathema B, Kreis-Wirth B, Barry 3rd CE, et al. Differential monocyte activation underlies strain-specific Mycobacterium tuberculosis pathogenesis. Infect Immun. 2004;72:5511-4.

4. Mahon RN, Rojas RE, Fulton SA, Franko JL, Harding CV, Boom WH. Mycobacterium tuberculosis cell wall glycolipids directly inhibit CD4+ T-cell activation by interfering with proximal T-cell-receptor signaling. Infect Immun. 2009;77:4574-83.

5. Fortune SM, Solache A, Jaeger A, Hill PJ, Belisle JT, Bloom BR, et al. Mycobacterium tuberculosis inhibits macrophage responses to IFN-gamma through myeloid differentiation factor 88-dependent and -independent mechanisms. J Immunol. 2004;172:6272-80. 
6. Hunter RL, Olsen MR, Jagannath C, Actor JK. Multiple roles of cord factor in the pathogenesis of primary, secondary, and cavitary tuberculosis, including a revised description of the pathology of secondary disease. Ann Clin Lab Sci. 2006;36:371-86.

7. Vergne I, Chua J, Lee HH, Lucas M, Belisle J, Deretic V. Mechanism of phagolysosome biogenesis block by viable Mycobacterium tuberculosis. Proc Natl Acad Sci U S A. 2005;102:4033-8.

8. Saavedra R, Segura E, Tenorio EP, López-Marín LM. Mycobacterial trehalosecontaining glycolipid with immunomodulatory activity on human CD4+ and CD8+ T-cells. Microbes Infect. 2006;8:533-40.

9. Chesne-Seck ML, Barilone N, Boudou F, Gonzalo Asencio J, Kolattukudy PE, Martín C, et al. A point mutation in the two-component regulator PhoPPhoR accounts for the absence of polyketide-derived acyltrehaloses but not that of phthiocerol dimycocerosates in Mycobacterium tuberculosis H37Ra. J Bateriol. 2008;190(4):1329-34.

10. Gautier N, López-Marín LM, Lanéelle MA. Daffé. Structure of mycoside F, a family of trehalose-containing glycolipids of Mycobacterium fortuitum. FEMS Microbiol Lett. 1992;77:81-7.

11. Escamilla L, Mancilla R, Glender W, Lopez-Marin LM. Mycobacterium fortuitum glycolipids for the serodiagnosis of pulmonary tuberculosis. Amer J Resp Crit Care Med. 1996;154:1864-7.

12. MacMicking JD, North RJ, LaCourse R, Mudgett JS, Shah SK, Nathan CF. Identification of nitric oxide synthase as a protective lo cus against tuberculosis. Proc Natl Acad Sci U S A. 1997:94:5243-8.

13. Axelrod S, Oschkinat H, Enders J, Schlegel B, Brinkmann V, Kaufmann SH, et al. Delay of phagosome maturation by a mycobacterial lipid is reversed by nitric oxide. Cell Microbiol. 2008;10:1530-45.

14. Rich EA, Torres M, Sada E, Finegan CK, Hamilton BD, Toossi Z Mycobacterium tuberculosis (MTB)-stimulated production of nitric oxide by human alveolar macrophages and relationship of nitric oxide production to growth inhibition of MTB. Tuber Lung Dis. 1997;78:247-55.

15. Nicholson S, Bonecini-Almeida Mda G, Silva JR LE, Nathan C, Xie QW, Mumford $R$, et al. Inducible nitric oxide synthase in pulmonary alveolar macrophages from patients with tuberculosis. J Exp Med. 1996;183:2293-302.

16. Wang CH, Liu CY, Lin HC, Yu CT, Chung KF, Kuo HP. Increased exhaled nitric oxide in active pulmonary tuberculosis due to inducible NO synthase upregulation in alveolar macrophages. Eur Respir J. 1998:11:809-15.

17. Facchetti F, Vermi W, Fiorentini S, Chilosi M, Caruso A, Duse M, et al. Expression of inducible nitric oxide synthase in human granulomas and histiocytic reactions. Am J Pathol. 1999;154:145-52.

18. Pereira-Suárez AL, Estrada-Chávez C, Arriaga-Díaz C, Espinosa-Cueto P, Mancilla R. Coexpression of NRAMP1, iNOS, and nitrotyrosine in bovine tuberculosis. Vet Pathol. 2006;43:709-17.

19. Gómez LM, Anaya JM, Vilchez JR, Cadena J, Hinojosa R, Vélez L, et al. A polymorphism in the inducible nitric oxide synthase gene is associated with tuberculosis. Tuberculosis. 2007;87(4):288-94.

20. Brugmann WB, Firmani MA. Low concentrations of nitric oxide exert a hormetic effect on Mycobacterium tuberculosis in vitro. J Clin Microbiol. 2005;43:4844-6.

21. Rhee KY, Erdjument-Bromage $H$, Tempst P, Nathan CF. S-nitroso proteome of Mycobacterium tuberculosis: Enzymes of intermediary metabolism and antioxidant defense. Proc Natl Acad Sci U S A. 2005;102:467-72.

22. Darwin KH, Ehrt S, Gutierrez-Ramos JC, Weich N, Nathan CF. The proteasome of Mycobacterium tuberculosis is required for resistance to nitric oxide. Science. 2003;302:1963-6.

23. Muñoz M, Lanéelle MA, Luquin M, Torrelles J, Julián E, Ausina V, et al. Occurrence of an antigenic triacyl trehalose in clinical isolates and reference strains of Mycobacterium tuberculosis. FEMS Microbiol Lett. 1997;157:251-9.

24. Minnikin DE, Kremer L, Dover LG, Besra GS. The methyl-branched fortifications of Mycobacterium tuberculosis. Chemistry Biol. 2002;9:545-53.

\section{Submit your next manuscript to BioMed Central and take full advantage of:}

- Convenient online submission

- Thorough peer review

- No space constraints or color figure charges

- Immediate publication on acceptance

- Inclusion in PubMed, CAS, Scopus and Google Scholar

- Research which is freely available for redistribution

Submit your manuscript at www.biomedcentral.com/submit 